\title{
Dexmedetomidine Attenuates Lipopolysaccharide Induced MCP-1 Expression in Primary Astrocyte
}

\author{
Huan Liu, ${ }^{1}$ Jacques R. J. Davis, ${ }^{1}$ Zhi-Lin Wu, ${ }^{1}$ and Amro Faez Abdelgawad ${ }^{2}$ \\ ${ }^{1}$ Department of Anesthesiology, Union Hospital, Tongji Medical College, Huazhong University of Science and Technology, \\ Wuhan, China \\ ${ }^{2}$ Department of Anesthesiology, ICU and Pain Management, Benha University Hospital, Faculty of Medicine, Benha University, \\ Benha, Egypt
}

Correspondence should be addressed to Zhi-Lin Wu; 840916@qq.com

Received 20 June 2016; Revised 29 November 2016; Accepted 11 January 2017; Published 14 February 2017

Academic Editor: Maja Surbatovic

Copyright (C) 2017 Huan Liu et al. This is an open access article distributed under the Creative Commons Attribution License, which permits unrestricted use, distribution, and reproduction in any medium, provided the original work is properly cited.

Background. Neuroinflammation which presents as a possible mechanism of delirium is associated with MCP-1, an important proinflammatory factor which is expressed on astrocytes. It is known that dexmedetomidine (DEX) possesses potent antiinflammatory properties. This study aimed to investigate the potential effects of DEX on the production of MCP-1 in lipopolysaccharide-stimulated astrocytes. Materials and Methods. Astrocytes were treated with LPS (10 ng/ml, $50 \mathrm{ng} / \mathrm{ml}, 100 \mathrm{ng} / \mathrm{ml}$, and $1000 \mathrm{ng} / \mathrm{ml})$, DEX (500 ng/mL), LPS (100 ng/ml), and DEX (10, 100, and $500 \mathrm{ng} / \mathrm{mL})$ for a duration of three hours; expression levels of MCP-1 were measured by real-time PCR. The double immunofluorescence staining protocol was utilized to determine the expression of $\alpha 2$-adrenoceptors ( $\alpha 2 \mathrm{AR}$ ) and glial fibrillary acidic protein (GFAP) on astrocytes. Results. Expressions of MCP-1 mRNA in astrocytes were induced dose-dependently by LPS. Administration of DEX significantly inhibited the expression of MCP1 mRNA $(P<0.001)$. Double immunofluorescence assay showed that $\alpha 2$ AR colocalize with GFAP, which indicates the expression of $\alpha 2$-adrenoceptors in astrocytes. Conclusions. DEX is a potent suppressor of MCP-1 in astrocytes induced with lipopolysaccharide through $\alpha_{2} \mathrm{~A}$-adrenergic receptors, which potentially explains its beneficial effects in the treatment of delirium by attenuating neuroinflammation.

\section{Introduction}

Delirium is the most common psychiatric syndrome for senior ICU patients [1], often resulting in higher mortality rates and increased duration of hospital stay $[2,3]$. Its mechanism has not been completely understood yet. A line of studies indicated that neuroinflammation may play a role in its pathogenesis [4-6]. Astrocytes, the main component of glial cells in central nervous system, function not only as the basic structure skeleton, but also as a key participant in the activity of the central nervous system [7]. Immunologically they maintain a dormant state until aroused by the stimulation of pain, ischemia, or other injuries. The astrocytes will then be activated, resulting in large numbers of proinflammatory factors, leading to cytokine synthesis and resulting in neuroinflammation [8].

Of all the cytokines secreted by astrocytes, MCP-1 is the one that has been elucidated clearly. It is a potent chemotoxin and activation factor for monocytes, which can modulate the synthesis of cytokines and adhesion molecules on the cell surface, thus being an important proinflammation factor [9]. Studies showed that MCP-1 plays a pivotal role for monocyte recruitment in spinal trauma and nerve inflammation $[10,11]$. Inhibiting MCP-1 secretion can dramatically attenuate the inflammation response [12]. Therefore inhibiting the expression of MCP-1 in astrocytes may provide a potential method for the treatment of nerve inflammation and delirium.

DEX is a highly selective $\alpha 2 \mathrm{AR}$ agonist. A number of studies showed that it possesses anti-inflammatory capabilities [13-15]. It was found to reduce the systematic inflammatory responses in rats with endotoxemia, regulate inflammatory responses of macrophages induced by LPS [16, 17], alleviate myocardial ischemia-reperfusion injury, and reduce infarction size [18]. In the central nervous system, DEX is proven to promote neurotrophic-factor secretion in astrocytes and exerts a neuroprotective effect [19]. DEX is also a potent 
suppressor of lipopolysaccharide induced inflammation in activated microglial cells [20]. However, little is known regarding the effects of DEX on the inflammation of astrocytes. The following research aims to investigate the effects of DEX on the production of MCP-1 in LPS activated astrocytes and provide useful and applicable information to reveal the potential therapeutic value of DEX in the treatment of delirium in ICU patients.

\section{Materials and Methods}

2.1. Primary Cortical Astrocyte Culture Preparation. Primary cortical astrocytes were obtained from 1-day-old neonatal Sprague-Dawley rats. The detailed protocol was previously described [21]. Briefly, the cerebral cortices of the rats were minced with a mesh bag $(100 \mathrm{~mm})$. Dissociated cortical cells were then suspended in Dulbecco's modified Eagle medium containing $10 \%$ heat-inactivated fetal bovine serum and $1 \%$ penicillin/streptomycin and plated on $25 \mathrm{~cm}^{2}$ flasks at a density of 600,000 cells $/ \mathrm{cm}^{2}$. Monolayers of type 1 astrocytes were obtained 6-8 days after plating. The confluent cultures were shaken at $(200 \mathrm{rpm}, 37)$ for 4 hours to separate the remaining microglial cells and oligodendroglial cells. The purity of primary cortical astrocytes was assessed by immunofluorescent staining for GFAP (Sigma, USA). Once established that more than $95 \%$ of the cultured cells were GFAP positive, d-cAMP $(150 \mu \mathrm{mlo} / \mathrm{L})$ was added to induce cell maturation over a duration of 3 to 4 days.

2.2. Immunofluorescence Assay. Primary astrocytes were prepared from the cerebral cortex of neonatal rats as described above. Astrocytes were then cultured on cover glasses $(18 \mathrm{~mm}$ * $18 \mathrm{~mm}$ ) placed in the 6-well plates. Dibutyryl cAMP (d-cAMP, 0.15 mM, Sigma, St. Louis, MO) was added to induce differentiation when cells attained 50\%-80\% confluence. Then serum-containing medium was abandoned and cover glasses were washed one time with $0.01 \mathrm{M}$ PBS. The astrocytes were then fixed with $4 \%$ paraformaldehyde for 30 minutes. The slides were initially blocked with 5\% goatserum for 2 hours at room temperature and then incubated with the following two primary antibodies: $\alpha 2 \mathrm{~A}$ (rabbit, 1:50, Santa Cruz Biotechnology, Inc., Santa Cruz, CA) and GAPDH (mouse, 1:20,000, Millipore, Billerica, MA, USA) at $4^{\circ} \mathrm{C}$ overnight. After washing them with PBS three times, the slides were then incubated free from light with Cy3or FITC-conjugated secondary antibodies (1:1000, Jackson ImmunoResearch, West Grove, PA, USA) for 2 hours at room temperature, rinsing well and sealing the slides with $30 \mu \mathrm{l}$ mounting medium. The stained sections were examined with a Leica fluorescence microscope, and images were captured with a CCD Spot camera. Some sections with double staining of $\alpha 2 \mathrm{~A}$ and GFAP were imaged with Leica SP8 Gated STED confocal microscope.

2.3. Experiment Protocols. In the preliminary experiment, we aimed to achieve the optimum dose of LPS for astrocyte, so cells (approximately 1,105 cells/mL) were seeded in six-well plates before being subjected to treatments. Five groups of astrocytes were subjected to various treatments. In group 1, cells were incubated in OPT for 3 hours as a control. In groups $2-5$, cells were treated with $10 \mathrm{ng} / \mathrm{ml}, 50 \mathrm{ng} / \mathrm{ml}, 100 \mathrm{ng} / \mathrm{ml}$, and $1000 \mathrm{ng} / \mathrm{ml}$ LPS; real-time PCR was used to measure MCP-1 mRNA expression. We established that astrocytes were most sensitive to $100 \mathrm{ng} / \mathrm{ml}$ LPS. Thus we utilized the optimum dose of $100 \mathrm{ng} / \mathrm{ml}$ for the following experiments. Another six groups of cells were subjected to various treatments. In group 1 cells were incubated in OPT for 3 hours as a control. In group 2, cells were treated with $100 \mathrm{ng} / \mathrm{ml}$ LPS for 3 hours; in group 3, cells were treated with $500 \mathrm{ng} / \mathrm{ml}$ DEX for 3 hours. In groups 4-5, cells were pretreated with $10 \mathrm{ng} / \mathrm{ml}, 100 \mathrm{ng} / \mathrm{ml}$, and $500 \mathrm{ng} / \mathrm{ml} \mathrm{DEX}$ for 1/2-hour and then with $100 \mathrm{ng} / \mathrm{ml} \mathrm{LPS}$ for 3 hours.

2.4. Reverse Transcription and Polymerase Chain Reaction. Total RNA were prepared from astrocytes by utilizing the Trizol reagent (Invitrogen Corporation, Carlsbad, CA) according to the manufacturer's protocol. Total RNA was reversely transcribed by using Moloney murine leukemia virus reverse transcriptase (Promega, Madison, WI). Polymerase chain reaction (PCR) primers were as follows: MCP1, sense: $5^{\prime}$-ACTTGACCCATAAATCTGA-3', antisense: $5^{\prime}$ TGGAAGGGAALAGTGTAAT- $3^{\prime}$; GAPDH: sense: $5^{\prime}$-TCC TAC CCC CAA TGT ATC CG-3', antisense: $5^{\prime}$-CCT TTA GTGGGC CCT CGG-3. The following PCR condition was applied: denaturation at $95^{\circ} \mathrm{C}$ for $30 \mathrm{~s}$, then 40 cycles of denaturation at $95^{\circ} \mathrm{C}$ for $5 \mathrm{~s}$, annealing at $56 \sim 60^{\circ} \mathrm{C}$ for $30 \mathrm{~s}$, and extension at $72^{\circ} \mathrm{C}$ for $30 \mathrm{~s}$. The PCR products were photographed after electrophoresis through agarose gel, stained with ethidium bromide, and analyzed with RotorGene Corbett software.

2.5. Statistical Analysis. All results observed were expressed as the means \pm standard error of the mean. Intragroup comparisons were made by one way ANOVA. Binary comparisons were made by Student's $t$-test. A value of $P<0.05$ was accepted as statistically significant.

\section{Results}

3.1. LPS Stimulated MCP-1 Releasing in Astrocyte. Before harvesting, morphology examined under microscope showed astrocyte adhesion on the wall, with cell body contracting, multiple cytoprocesses, and no floating. After 3 hours of coculture with LPS $10 \mathrm{ng} / \mathrm{ml}, 50 \mathrm{ng} / \mathrm{ml}, 100 \mathrm{ng} / \mathrm{ml}$, and $1000 \mathrm{ng} / \mathrm{ml}$, expressions of MCP-1 mRNA were measured. There was no observable difference on MCP-1 between the group containing $10 \mathrm{ng} / \mathrm{ml}$ and the group containing $50 \mathrm{ng} / \mathrm{ml}$.

Consequently the expression of MCP-1 mRNA increased dose-dependently with LPS (Figure 1). Since astrocytes were most sensitive to a dose of $100 \mathrm{ng} / \mathrm{ml} \mathrm{LPS}$, this concentration of LPS was utilized in the following study.

3.2. DEX Suppresses MCP-1 Release in LPS-Stimulated Astrocytes. Expression of MCP-1 mRNA increased 37-fold in astrocytes that were being stimulated with $100 \mathrm{ng} / \mathrm{ml} \mathrm{LPS}$ in comparison to the control group, while, in groups pretreated with DEX (10 ng/ml, $100 \mathrm{ng} / \mathrm{ml}$, and $500 \mathrm{ng} / \mathrm{ml}$ ) for $30 \mathrm{~min}$, 


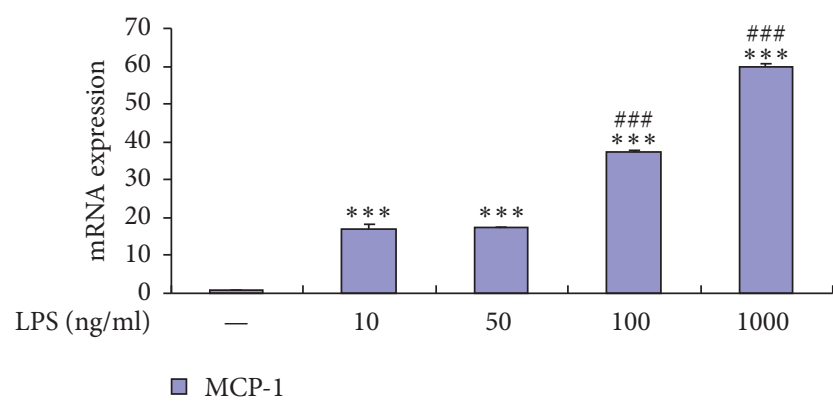

FIGURE 1: LPS dose-dependently increased stimulation of astrocytes release of MCP-1. RT-PCR shows that LPS dose-dependently increased release of MCP-1 from astrocytes. Data represent mean \pm standard error of the mean of four independent experiments. ${ }^{* * *} \mathrm{P}<$ 0.001 compared to control group; ${ }^{\# \#} P<0.001$ LPS $100 \mathrm{ng} / \mathrm{ml}$ compared to LPS $50 \mathrm{ng} / \mathrm{ml}$ group, LPS $1000 \mathrm{ng} / \mathrm{ml}$ compared to LPS $100 \mathrm{ng} / \mathrm{ml}$ group.

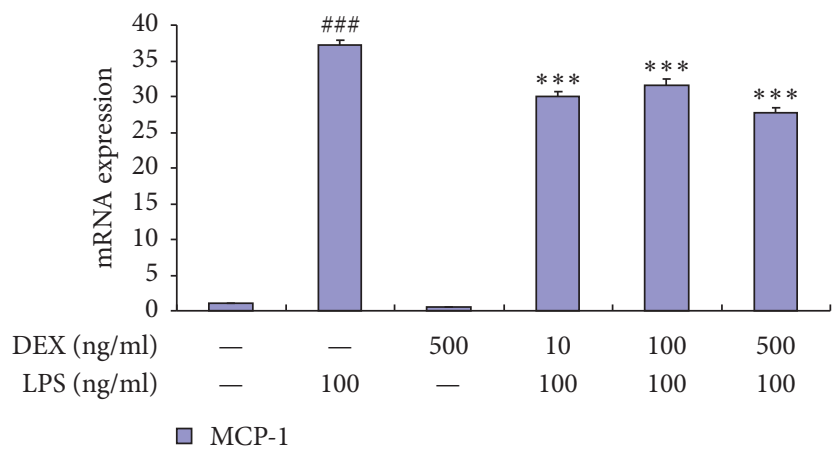

FIGURE 2: Dexmedetomidine significantly inhibited the release of MCP-1 in activated astrocytes. RT-PCR shows that dexmedetomidine significantly inhibited the release of MCP-1 in activated astrocytes. Data represent mean \pm standard error of the mean of four independent experiments. ${ }^{\# \#} P<0.001$ versus control group; ${ }^{* * *} P<0.001$ versus LPS $100 \mathrm{ng} / \mathrm{ml}$ group.

MCP-1 mRNA expression decreased dramatically under the identical stimulation of LPS.

To exclude the possible toxic effects of high concentration DEX, maturely differentiated astrocytes were pretreated with $500 \mathrm{ng} / \mathrm{ml}$ DEX alone for 3 hours. The expression of MCP-1 mRNA was then observed to remain the same as the control group. This suggested that DEX possessed no poisonous effect on astrocytes (Figure 2).

3.3. DEX Suppresses the MCP-1 Releasing through $\alpha 2 A R$. Double immunofluorescence displayed that $\alpha 2 \mathrm{AR}$ colocalize with GFAP, which evidently proved the existence of $\alpha 2 \mathrm{AR}$ in astrocytes (Figure 3). As a specific agonist of $\alpha 2 \mathrm{AR}, \mathrm{DEX}$ might potentially suppress the release of MCP-1 through this pathway.

\section{Discussion}

This is the first study to demonstrate that DEX was capable of attenuating the expression of MCP-1 mRNA, a potent proinflammatory factor in primary cultured astrocytes activated by LPS. This provides additional evidence for DEX's therapeutic value in neuroinflammation and related illnesses such as delirium.

Astrocytes are the chief components of glial cells in the central nervous system and maintain a key role in the process of neuroprotection against various kinds of injuries [22, 23]. They specially buffer ions like $\mathrm{K}^{+}$, scavenge free radicals for the maintenance of the extracellular environment, provide substrates for neurotransmitters and antioxidants, secrete neurotrophic factors, promote much needed neovascularization, and assist in the regeneration of synapses and neurons [24-28]. Astrocytes can be activated by inflammatory mediators in a wide range of CNS pathologies, including ischemia, infection, and neurotrauma [29-31]. Through the release of numerous proinflammatory cytokines and chemokines, astrocytes are thereby involved in the process of immune response initiation and regulation [32]. Astrocytes activation is thought to be protective via destruction of pathogens, removal of debris, and promotion of tissue repair [33]. However, prolonged and sustained inflammation may have cytotoxic effects, aggravating the incidence and the severity of the disease. Symptoms such as fever, somnolence, hyperalgia, and allodynia are all related to the neuroinflammation process [34].

Of the chemokines, which astrocytes released, MCP-1 is the one that has been clarified quite clearly. It is produced by monocytes, fibroblast cells, B cells, and endothelium and glial cells. In the central nervous system, the astrocytes are the main source [35]. It chemoattracts and activates monocytes, modulates cytokines and adhesion molecule production, and initiates inflammatory responses [36]. MCP-1 receptors on the surface of astrocytes modulate the production with regard to a positive feedback mechanism. MCP-1 could possibly be involved in secondary inflammatory response in the site of spinal injury [37]. It has been observed to cause neuronal death via direct apoptotic mechanisms through specific cell surface chemokine receptors [38]. MCP-1 receptor antagonists dramatically controlled the inflammation response and enhanced neurological recovery in rats with spinalcord contusion injuries [10]. With administration of MCP1-antibody, cases of neuropathologic pain in sciatic and L5 spinal nerve ligation models can be significantly alleviated [12].

Nonselective alpha adrenergic receptor agonists such as noradrenaline can reduce the production of MCP-1 in ratcultured astrocytes in the presence of an inflammatory stimulus [39], such as LPS. The effect was reversed by alpha-2 adrenergic receptor antagonist Yohimbine which indicates alpha-2 adrenergic receptors are important cell signaling pathways for modulating the release of inflammatory cytokines [40].

DEX, an alpha-2 agonist, is a widely used sedative in intensive care units. Numerous studies revealed that, other than its sedation effect, DEX possesses potent anti-inflammation capabilities as well as being greatly beneficial as a neuroprotective agent [41]. The aim of this research was to investigate the effect of DEX on the production of MCP-1 in primary cultured astrocytes activated by LPS. LPS is a potent stimulus 

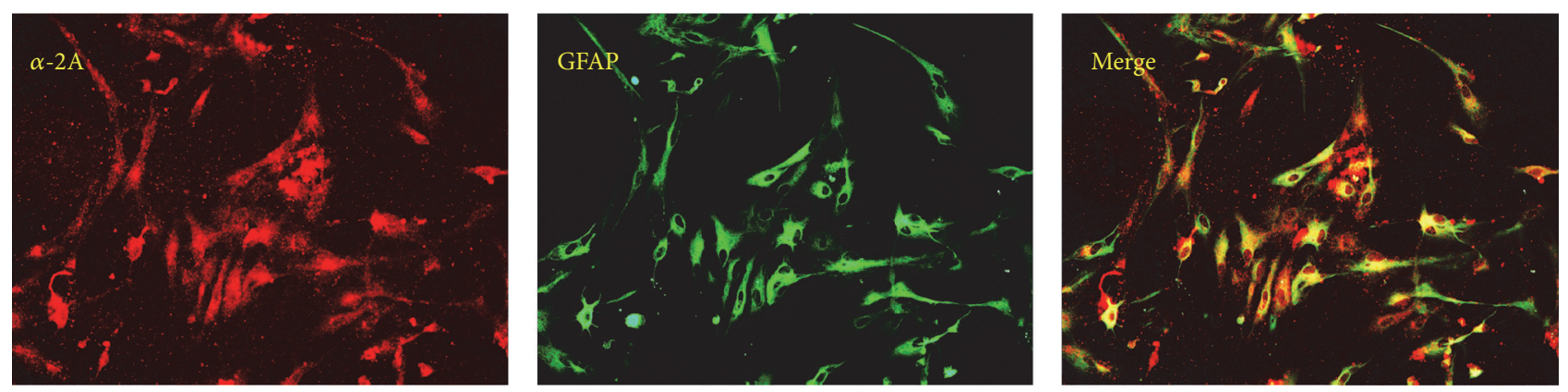

FIGURE 3: Double immunofluorescence exhibited that $\alpha 2 \mathrm{~A}$-adrenoreceptors ( $\alpha 2 \mathrm{~A}-\mathrm{R})$ colocalize with (a) glial fibrillary acidic proteins (GFAP; an astrocytic marker). Scale bar $=20 \mu \mathrm{m}$.

which induces a process of an inflammation response in endotoxemia. Firstly we studied the most optimum dose of LPS for stimulating the release of MCP-1 in astrocyte. We used $50 \mathrm{ng} / \mathrm{ml}, 100 \mathrm{ng} / \mathrm{ml}$, and $1000 \mathrm{ng} / \mathrm{ml}$ LPS in this case for the stimulation of astrocytes and found that, with a dose of $100 \mathrm{ng} / \mathrm{ml}$ LPS, stimulation of astrocytes displayed the most sensitive reaction in regard to the release of MCP-1. After establishing the correct and most applicable dose of LPS, we pretreated astrocytes with $10 \mathrm{ng} / \mathrm{ml}, 50 \mathrm{ng} / \mathrm{ml}$, and $500 \mathrm{ng} / \mathrm{ml}$ dexmedetomidine and then with $100 \mathrm{ng} / \mathrm{ml}$ LPS stimulation. All groups showed that there was a decrease in the rate of synthesis of MCP-1 RNA. To exclude the toxic effects of DEX regarding astrocytes, astrocytes were treated with a high dose of DEX alone. Results indicated that there was no observable difference compared to the control group. This suggested that DEX possesses no toxic effect on astrocytes.

DEX's capability of organ protection has been confirmed by numerous studies. DEX inhibits cell apoptosis and death and increases the survival rate of neurons by modulating the release of catecholamine and glutamate in the central nervous system [42]. Research indicated that DEX can increase survival rate of rats diseased by septic shock in manner of decreasing systematic inflammation [16]. DEX suppresses the release of cytokines IL-1 $\beta$, TNF- $\alpha$, and IL- 6 and promotes the recovery of spinal injury in rats [15]. Besides its antiinflammation capability, DEX promotes the release of glial cell line-derived neurotrophic factors in rat astrocytes, for neuronal and synapse regeneration [43]. DEX has no direct cytoprotective effect on $\mathrm{H}_{2} \mathrm{O}_{2}$ exposed neurons; however clinically relevant concentrations of DEX are neuroprotective against oxidative damage due to the stimulation of astrocyticadrenoceptors, causing release of HB-EGF which in turn activates neuronal EGF receptors [44].

However, it still remains unclear whether DEX has a direct effect on anti-inflammation of astrocytes or not. In our research, primary cultured astrocytes were pretreated with different doses of DEX and then stimulated with $100 \mathrm{ng} / \mathrm{ml}$ LPS; real-time PCR indicated that the following concentrations: 10,100 , and $500 \mathrm{ng} / \mathrm{ml} \mathrm{DEX}$, dramatically inhibited the release of MCP-1 mRNA. Thus, these results indicate that DEX possesses the capability of inhibiting the production of MCP-1 on astrocytes.
There are however some limits within our study. Firstly, the clinical therapeutic plasma concentration of DEX is 0.3$2 \mathrm{ng} / \mathrm{ml}$; research suggests that $1 \mathrm{ng} / \mathrm{ml} \mathrm{DEX}$ has no observable effect on the microglial cell inflammatory response. Our research suggested that $10 \mathrm{ng} / \mathrm{ml} \mathrm{DEX}$ inhibits the release of MCP-1. Whether a lower dose of DEX could possess the same effect still remains to be known. High concentrations of DEX can increase free cytosolic calcium concentration in astrocytes. The effect is partly blocked by Yohimbine and by Idazoxan, an inhibitor at the imidazoline-preference site [45]. The molecular signaling pathway of DEX regarding the production of MCP-1 in LPS-stimulated astrocytes is yet to be investigated.

In summary, this study indicates that DEX possesses the potential to decrease inflammatory response by inhibiting MCP- 1 expression through $\alpha 2 \mathrm{AR}$ on astrocytes and in addition exerts a protective effect on neuroinflammation. This research provides applicable data and results which indicate the potential value of DEX in the treatment of delirium in ICU patients.

\section{Competing Interests}

The authors declare that there is no conflict of interests regarding the publication of this article.

\section{References}

[1] M. C. Marshall and M. D. Soucy, "Delirium in the intensive care unit," Critical Care Nursing Quarterly, vol. 26, no. 3, pp. 172-178, 2003.

[2] E. W. Ely, A. Shintani, B. Truman et al., "Delirium as a predictor of mortality in mechanically ventilated patients in the intensive care unit," Journal of the American Medical Association, vol. 291, no. 14, pp. 1753-1762, 2004.

[3] K. Rockwood, S. Cosway, D. Carver, P. Jarrett, K. Stadnyk, and J. Fisk, "The risk of dementia and death after delirium," Age and Ageing, vol. 28, no. 6, pp. 551-556, 1999.

[4] B. C. Van Munster, E. Aronica, A. H. Zwinderman, P. Eikelenboom, C. Cunningham, and S. E. J. A. De Rooij, "Neuroinflammation in delirium: a postmortem case-control study," Rejuvenation Research, vol. 14, no. 6, pp. 615-622, 2011. 
[5] J. Cerejeira, H. Firmino, A. Vaz-Serra, and E. B. MukaetovaLadinska, "The neuroinflammatory hypothesis of delirium," Acta Neuropathologica, vol. 119, no. 6, pp. 737-754, 2010.

[6] M. D. Ghnassia and G. Debray, "The indications and limitation of ketamine anesthsia in plastic surgery," Annales de chirurgie plastique, vol. 17, no. 1, pp. 58-60, 1972.

[7] A. Volterra and J. Meldolesi, "Astrocytes, from brain glue to communication elements: the revolution continues," Nature Reviews Neuroscience, vol. 6, no. 8, pp. 626-640, 2005.

[8] C. Giaume, A. Koulakoff, L. Roux, D. Holcman, and N. Rouach, "Astroglial networks: a step further in neuroglial and gliovascular interactions," Nature Reviews Neuroscience, vol. 11, no. 2, pp. 87-99, 2010.

[9] A. Bajetto, R. Bonavia, S. Barbero, T. Florio, and G. Schettini, "Chemokines and their receptors in the central nervous system," Frontiers in Neuroendocrinology, vol. 22, no. 3, pp. 147-184, 2001.

[10] M. Ma, T. Wei, L. Boring, I. F. Charo, R. M. Ransohoff, and L. B. Jakeman, "Monocyte recruitment and myelin removal are delayed following spinal cord injury in mice with CCR2 chemokine receptor deletion," Journal of Neuroscience Research, vol. 68, no. 6, pp. 691-702, 2002.

[11] M. Samama, A. Guyon, S. Millez, S. Myriam Dridi, and F. Gaultier, "Abcès migrateur de Chompret-L'Hirondel abscess," La Revue du praticien, vol. 64, no. 8, p. 1047, 2014.

[12] R. S. Ghirnikar, Y. L. Lee, and L. F. Eng, "Chemokine antagonist infusion promotes axonal sparing after spinal cord contusion injury in rat," Journal of Neuroscience Research, vol. 64, no. 6, pp. 582-589, 2001.

[13] M. Tasdogan, D. Memis, N. Sut, and M. Yuksel, "Results of a pilot study on the effects of propofol and dexmedetomidine on inflammatory responses and intraabdominal pressure in severe sepsis," Journal of Clinical Anesthesia, vol. 21, no. 6, pp. 394-400, 2009.

[14] T. Taniguchi, A. Kurita, K. Kobayashi, K. Yamamoto, and H. Inaba, "Dose- and time-related effects of dexmedetomidine on mortality and inflammatory responses to endotoxin-induced shock in rats," Journal of Anesthesia, vol. 22, no. 3, pp. 221-228, 2008.

[15] M. Can, S. Gul, S. Bektas, V. Hanci, and S. Acikgoz, "Effects of dexmedetomidine or methylprednisolone on inflammatory responses in spinal cord injury," Acta Anaesthesiologica Scandinavica, vol. 53, no. 8, pp. 1068-1072, 2009.

[16] T. Taniguchi, Y. Kidani, H. Kanakura, Y. Takemoto, and K. Yamamoto, "Effects of dexmedetomidine on mortality rate and inflammatory responses to endotoxin-induced shock in rats," Critical Care Medicine, vol. 32, no. 6, pp. 1322-1326, 2004.

[17] Y.-C. Lai, P.-S. Tsai, and C.-J. Huang, "Effects of dexmedetomidine on regulating endotoxin-induced up-regulation of inflammatory molecules in murine macrophages," Journal of Surgical Research, vol. 154, no. 2, pp. 212-219, 2009.

[18] H. Okada, T. Kurita, T. Mochizuki, K. Morita, and S. Sato, "The cardioprotective effect of dexmedetomidine on global ischaemia in isolated rat hearts," Resuscitation, vol. 74, no. 3, pp. 538-545, 2007.

[19] B. Li, T. Du, H. Li et al., "Signalling pathways for transactivation by dexmedetomidine of epidermal growth factor receptors in astrocytes and its paracrine effect on neurons," British Journal of Pharmacology, vol. 154, no. 1, pp. 191-203, 2008.

[20] M. Peng, Y.-L. Wang, C.-Y. Wang, and C. Chen, "Dexmedetomidine attenuates lipopolysaccharide-induced proinflammatory response in primary microglia," Journal of Surgical Research, vol. 179, no. 1, pp. E219-E225, 2013.
[21] K. Arai and E. H. Lo, "Astrocytes protect oligodendrocyte precursor cells via MEK/ERK and PI3K/Akt signaling," Journal of Neuroscience Research, vol. 88, no. 4, pp. 758-763, 2010.

[22] G. Trendelenburg and U. Dirnagl, "Neuroprotective role of astrocytes in cerebral ischemia: focus on ischemic preconditioning," GLIA, vol. 50, no. 4, pp. 307-320, 2005.

[23] K. S. Panickar and M. D. Noremberg, "Astrocytes in cerebral ischemic injury: morphological and general considerations," GLIA, vol. 50, no. 4, pp. 287-298, 2005.

[24] L. Hertz, E. Hansson, and L. Rönnbäck, "Signaling and gene expression in the neuron-glia unit during brain function and dysfunction: Holger Hydén in memoriam," Neurochemistry International, vol. 39, no. 3, pp. 227-252, 2001.

[25] A. Håberg, H. Qu, O. Sæther, G. Unsgård, O. Haraldseth, and U. Sonnewald, "Differences in neurotransmitter synthesis and intermediary metabolism between glutamatergic and GABAergic neurons during 4 hours of middle cerebral artery occlusion in the rat: the role of astrocytes in neuronal survival," Journal of Cerebral Blood Flow and Metabolism, vol. 21, no. 12, pp. 1451$1463,2001$.

[26] E. M. Blanc, A. J. Bruce-Keller, and M. P. Mattson, "Astrocytic gap junctional communication decreases neuronal vulnerability to oxidative stress-induced disruption of $\mathrm{Ca}^{2+}$ homeostasis and cell death," Journal of Neurochemistry, vol. 70, no. 3, pp. 958970, 1998.

[27] H. Song, C. F. Stevens, and F. H. Gage, "Astroglia induce neurogenesis from adult neural stem cells," Nature, vol. 417, no. 6884, pp. 39-44, 2002.

[28] D. A. Lim and A. Alvarez-Buylla, "Interaction between astrocytes and adult subventricular zone precursors stimulates neurogenesis," Proceedings of the National Academy of Sciences of the United States of America, vol. 96, no. 13, pp. 7526-7531, 1999.

[29] M. Bernaudin, A. Bellail, H. H. Marti et al., "Neurons and astrocytes express EPO mRNa: oxygen-sensing mechanisms that involve the redox-state of the brain," GLIA, vol. 30, no. 3, pp. 271-278, 2000.

[30] J. Badaut, L. Hirt, C. Granziera, J. Bogousslavsky, P. J. Magistretti, and L. Regli, "Astrocyte-specific expression of aquaporin9 in mouse brain is increased after transient focal cerebral ischemia," Journal of Cerebral Blood Flow and Metabolism, vol. 21, no. 5, pp. 477-482, 2001.

[31] S. Liu and T. Kielian, "MyD88 is pivotal for immune recognition of Citrobacter koseri and astrocyte activation during CNS infection," Journal of Neuroinflammation, vol. 8, article 35, 2011.

[32] K. M. Dhandapani, M. Hadman, L. De Sevilla, M. F. Wade, V. B. Mahesh, and D. W. Brann, "Astrocyte Protection of Neurons: role of transforming growth factor- $\beta$ signaling via a c-Jun-AP1 protective pathway," Journal of Biological Chemistry, vol. 278, no. 44, pp. 43329-43339, 2003.

[33] T. Nakayama, T. Momoki-Soga, and N. Inoue, "Astrocytederived factors instruct differentiation of embryonic stem cells into neurons," Neuroscience Research, vol. 46, no. 2, pp. 241-249, 2003.

[34] E. D. Milligan and L. R. Watkins, "Pathological and protective roles of glia in chronic pain," Nature Reviews Neuroscience, vol. 10, no. 1, pp. 23-36, 2009.

[35] S. B. McMahon, W. B. J. Cafferty, and F. Marchand, "Immune and glial cell factors as pain mediators and modulators," Experimental Neurology, vol. 192, no. 2, pp. 444-462, 2005.

[36] D. Huang, J. Wang, P. Kivisakk, B. J. Rollins, and R. M. Ransohoff, "Absence of monocyte chemoattractant protein 1 in 
mice leads to decreased local macrophage recruitment and antigen-specific T helper cell type 1 immune response in experimental autoimmune encephalomyelitis," Journal of Experimental Medicine, vol. 193, no. 6, p. 713, 2001.

[37] Y. L. Lee, K. Shih, P. Bao, R. S. Ghirnikar, and L. F. Eng, "Cytokine chemokine expression in contused rat spinal cord," Neurochemistry International, vol. 36, no. 4-5, pp. 417-425, 2000.

[38] G. Conductier, N. Blondeau, A. Guyon, J.-L. Nahon, and C. Rovère, "The role of monocyte chemoattractant protein MCP1/CCL2 in neuroinflammatory diseases," Journal of Neuroimmunology, vol. 224, no. 1-2, pp. 93-100, 2010.

[39] A. E. Hinojosa, J. R. Caso, B. García-Bueno, J. C. Leza, and J. L. M. Madrigal, "Dual effects of noradrenaline on astroglial production of chemokines and pro-inflammatory mediators," Journal of Neuroinflammation, vol. 10, article 81, 2013.

[40] A. E. Hinojosa, B. García-Bueno, J. C. Leza, and J. L. M. Madrigal, "Regulation of CCL2/MCP-1 production in astrocytes by desipramine and atomoxetine: involvement of $\alpha 2$ adrenergic receptors," Brain Research Bulletin, vol. 86, no. 5-6, pp. 326-333, 2011.

[41] A. Bekker and M. K. Sturaitis, "Dexmedetomidine for neurological surgery," Neurosurgery, vol. 57, supplement 1, pp. 1-10, 2005.

[42] K. Engelhard, C. Werner, E. Eberspächer et al., "The effect of the $\alpha 2$-agonist dexmedetomidine and the $\mathrm{N}$-methyl-D-aspartate antagonist $\mathrm{S}(+)$-ketamine on the expression of apoptosisregulating proteins after incomplete cerebral ischemia and reperfusion in rats," Anesthesia and Analgesia, vol. 96, no. 2, pp. 524-531, 2003.

[43] M. Yan, H. Dai, T. Ding et al., "Effects of dexmedetomidine on the release of glial cell line-derived neurotrophic factor from rat astrocyte cells," Neurochemistry International, vol. 58, no. 5, pp. 549-557, 2011.

[44] M. Zhang, X. Shan, L. Gu, L. Hertz, and L. Peng, "Dexmedetomidine causes neuroprotection via astrocytic $\alpha_{2}$-adrenergic receptor stimulation and HB-EGF release," journal of Anesthesiology and Clinical Science, vol. 2, 2013.

[45] Y. Chen, Z. Zhao, W. E. Code, and L. Hertz, "A correlation between dexmedetomidine-induced biphasic increases in free cytosolic calcium concentration and energy metabolism in astrocytes," Anesthesia and Analgesia, vol. 91, no. 2, pp. 353-357, 2000 . 


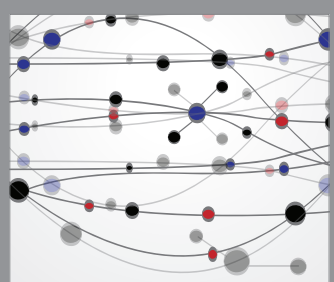

The Scientific World Journal
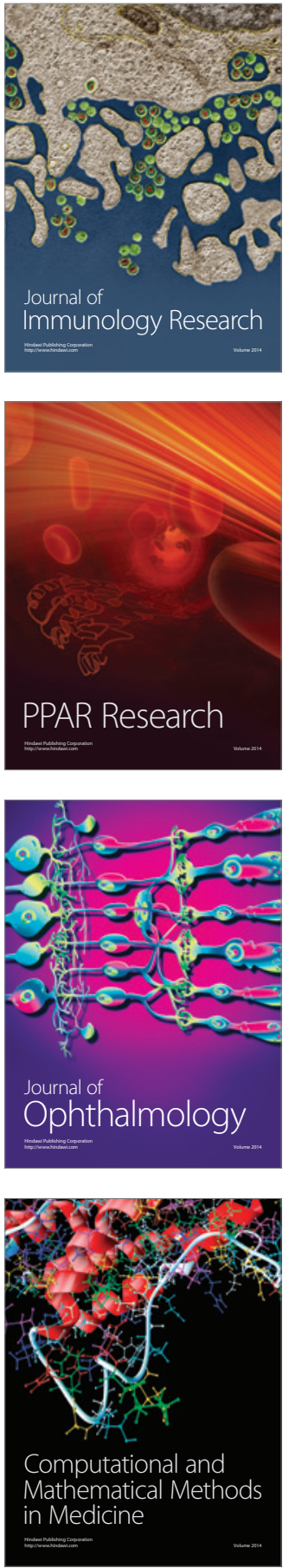

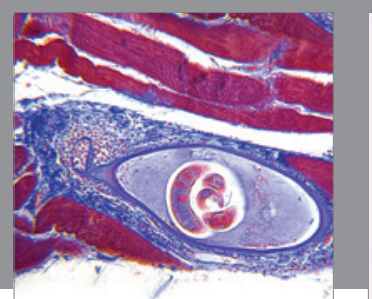

Gastroenterology Research and Practice
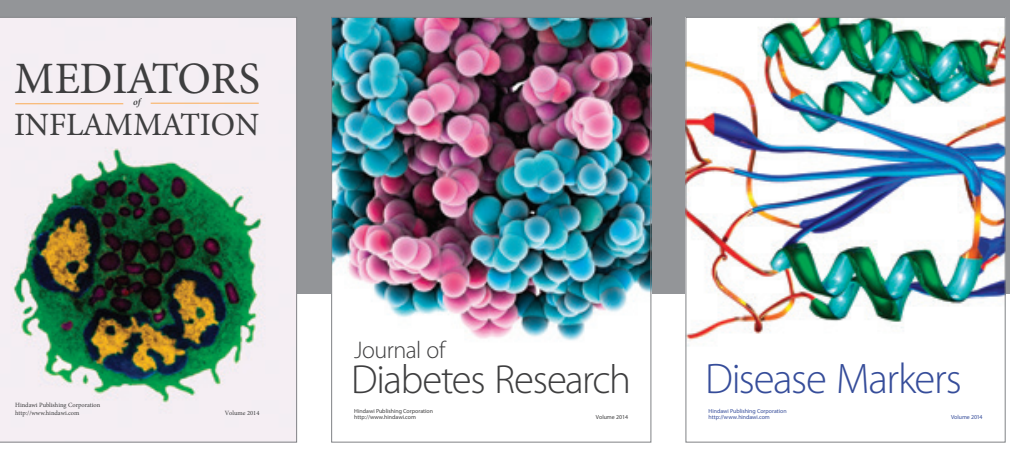

Disease Markers

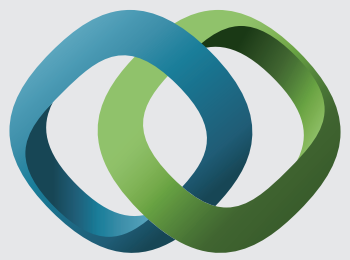

\section{Hindawi}

Submit your manuscripts at

https://www.hindawi.com
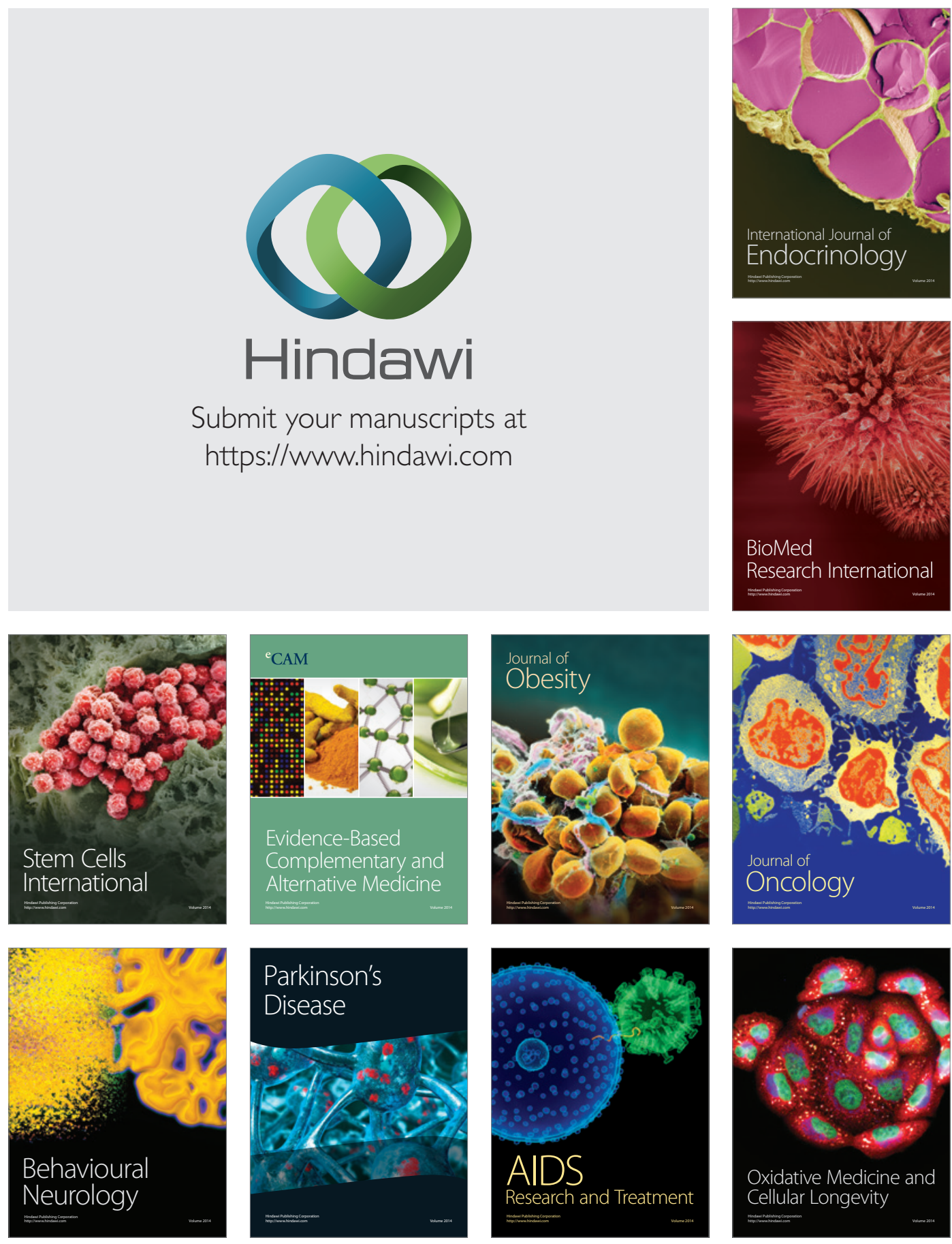